\title{
Changes of diapause and cold hardiness in the Shonai ecotype larvae of the rice stem borer, Chilo suppressalis Walker (Lepidoptera: Pyralidae) during overwintering
}

\author{
Michiyo Goto, * Yi-Ping Li and Takashi Honma \\ Department of Bioprocess Engineering, Faculty of Agriculture, Yamagata University, Tsuruoka 997-8555, Japan \\ (Received 12 July 2000; Accepted 19 March 2001)
}

\begin{abstract}
Larvae of the Shonai ecotype of the rice stem borer, Chilo suppressalis, were in diapause until October when the ambient temperature was relatively high and most of the larvae terminated diapause in November before winter. The cold hardiness of field-collected larvae was low at the diapause stage, but relatively high at the post-diapause stage. Glycerol was scarcely detected at the diapause stage, but its content increased at the post-diapause stage. Conversion between glycogen and glycerol was found in diapausing larvae during temperature acclimation $\left(0-30^{\circ} \mathrm{C}\right)$, but a time lag between glycogen loss and glycerol increase was detected under field conditions. The results obtained for the Shonai ecotype are compared with those of the other main ecotype of this species, the Saigoku ecotype.
\end{abstract}

Key words: Chilo suppressalis, Shonai ecotype, glycerol, diapause, cold hardiness

\section{INTRODUCTION}

Japan is a long $\left(24-45^{\circ} \mathrm{N}\right)$ and narrow island country with climates varying from sub-tropical to cool temperate. The rice stem borer, Chilo suppressalis Walker, which is distributed all over the islands, is one of the most important rice pests in Japan. The borer has a bivoltine life cycle in most parts of Japan, except for the southern parts of Shikoku and Kyushu islands, where it is trivoltine, and Hokkaido and some parts of northern Honshu, where it is univoltine (Ishikura, 1955; Fukaya and Mitsuhashi, 1961; Kishino, 1974). The bivoltine borer in Japan is divided into at least two ecotypes, "the Shonai ecotype" and "the Saigoku ecotype" according to physiological properties (Fukaya and Mitsuhashi, 1961). The Shonai ecotype is distributed in the northern part of Japan, whereas the Saigoku ecotype is in the southern part. Overwintering mature larvae of both ecotypes undergo a facultative diapause which is induced by photoperiods below $14 \mathrm{~h}$ in autumn (Inoue and Kamano, 1957; Kishino, 1974). The larval diapause of the Saigoku ecotype terminates in February, whereas in the Shonai ecotype, it terminates in November (Fukaya and Mitsuhashi, 1961). Ambient temperature in Japan is lowest in January and February.
Diapause in the Shonai ecotype terminates before the coldest season, and terminates in the Saigoku ecotype after the coldest season. To elucidate the difference in diapause termination between these two ecotypes, a preliminary study on the relationships between diapause and cold hardiness in each ecotype is required. The physiological bases for diapause and cold hardiness in the Saigoku ecotype have been elucidated (Tsumuki and Kanehisa, 1978, 1979, 1980; Tsumuki, 1990), but no systematic studies on the Shonai ecotype have been conducted.

Insects have evolved various adaptations to endure the adverse seasons in their life cycles. Low temperature is one of the major environmental obstacles to insect survival in temperate to arctic zones. Many insects inhabiting temperate zones endure environmental stresses by entering diapause (Tauber et al., 1986; Denlinger, 1991; Leather et al., 1993). Cold hardiness and winter diapause are essential for survival in most overwintering insects. Three main patterns between cold hardiness and diapause are found in insects. First, cold hardiness is closely related to diapause, and cold hardiness is a part of the physiological expression of the diapause syndrome (Tauber et al., 1986; Denlinger, 1991; Koštál and Šimek, 1995). Second, some

\footnotetext{
* To whom correspondence should be addressed at: E-mail: mgoto@tds1.tr.yamagata-u.ac.jp
} 
overwintering insects express maximal cold hardiness at the post-diapausing stage, and cold hardiness is inversely associated with diapause status (Goto et al., 1993a, b, 1998, 2001). Another pattern was found in some diapausing species at the non-diapausing stage. Cold hardiness is independent of diapause. Cold hardiness at the non-diapausing stage is not as high as that of the diapause stage reared at the same temperature, and is also low in response to temperature acclimation (Nordin et al., 1984; Chen et al., 1987). The aim of this study was to examine the characteristics of diapause and cold hardiness in the Shonai ecotype of overwintering (diapause and post-diapause) C. suppressalis larvae.

\section{MATERIALS AND METHODS}

Insects and acclimation. Overwintering larvae of $C$. suppressalis were collected from the paddy field in Takasaka in the Shonai district of Yamagata Prefecture $\left(38^{\circ} 5^{\prime} \mathrm{N}, 39^{\circ} 5^{\prime} \mathrm{E}\right)$ from September to January (September 14, October 14, November 14, December 14 and January 14) in 1995-96. In acclimation experiments, the larvae $(n=8)$ collected from the field in October were acclimated at 0, 10, 20 and $30^{\circ} \mathrm{C}$ for $15 \mathrm{~d}$ in the dark, respectively. Glycerol, trehalose, glycogen and lipid were measured after the treatment.

Ambient temperature. Field temperatures were automatically recorded with a meteorological instrument (NAKAASA, M806), which was set at the same sampling location.

Days before adult emergence. Overwintering larvae $(n=20)$ collected from the field every month were incubated at $25^{\circ} \mathrm{C}$ under a photoperiod of $12 \mathrm{~h}$ light and $12 \mathrm{~h}$ dark (12L-12D), and then adult emergence was observed every day for 90 days.

Survival rate after exposure to $-15^{\circ} \mathrm{C}$. Fieldcollected larvae $(n=20)$ were transferred into a temperature-controlled chamber, whose temperature was lowered at a rate of $5^{\circ} \mathrm{C} / \mathrm{h}$ till $-15^{\circ} \mathrm{C}$, held at $-15^{\circ} \mathrm{C}$ for $24 \mathrm{~h}$, and then slowly raised to $20^{\circ} \mathrm{C}$. After $24 \mathrm{~h}$ and $72 \mathrm{~h}$, the numbers of living and dead larvae were counted. Larvae showing no movement and loose body segments were considered as dead.

Chemical analyses. Glycerol and trehalose were measured by gas liquid chromatography as described by Goto (1995). Glycogen was determined by the phenol/sulfuric acid method (Goto et al., 1993a). Lipids were assayed as described by Goto et al. (1998).

Statistical analysis. Statistical analysis was carried out by one-way analysis of variance, followed by Tukey's multi-range test, using the SAS statistics package.

\section{RESULTS}

\section{Changes in the intensity of diapause and cold} hardiness during overwintering

The average ambient temperature in the Shonai district (Takasaka farm) in 1995-96 was about $19.0^{\circ} \mathrm{C}$ in September, $16.0^{\circ} \mathrm{C}$ in October, $8.5^{\circ} \mathrm{C}$ in November, then reached a minimum near $0^{\circ} \mathrm{C}$ in January (Fig. 1A).
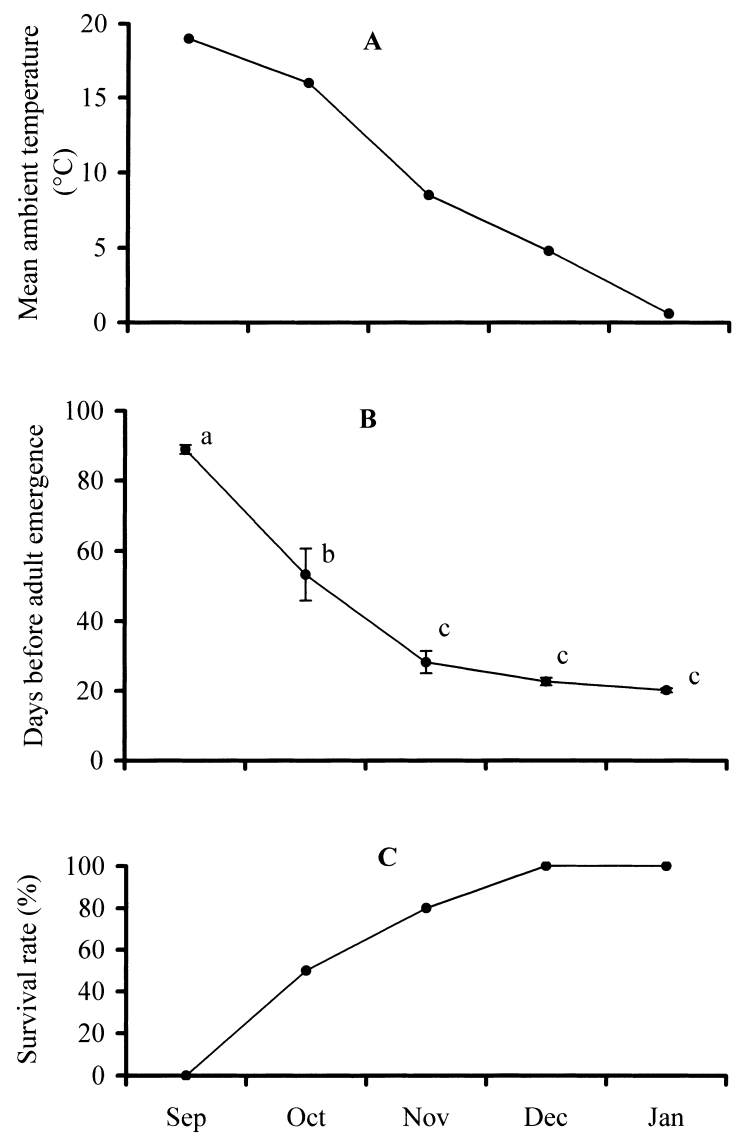

Fig. 1. Seasonal changes in average ambient temperature at Shonai, Yamagata (A), days before adult emergence (B) and survival rates at $-15^{\circ} \mathrm{C}$ for $24 \mathrm{~h}(\mathrm{C})$ in overwintering larvae of the rice stem borer $C$. suppressalis. Each value represents the mean $( \pm$ SEM). Values labeled with the same letters on the same line are not significantly different at the $5 \%$ level by Tukey's test after ANOVA. The number of replicates is 20 in (B) and (C). 
A significant difference in the period required for adult emergence at $25^{\circ} \mathrm{C}$ incubation was observed among the different collecting months $(F=$ $60.93, p<0.001$; Fig. 1B). The period decreased from 88.9 days in September to 53.3 days in October $(p<0.05)$, and then to 27.3 days in November $(p<0.05)$. Thereafter, the periods were almost constant from November to January.

Overwintering larvae were exposed to $-15^{\circ} \mathrm{C}$ for $24 \mathrm{~h}$ to examine their cold hardiness (Fig. 1C). No larvae collected in September survived after the subzero temperature exposure. However $50 \%$ of the larvae collected in October and $80 \%$ of the larvae collected in November survived. All larvae collected in December and January survived after the subzero temperature exposure, showing that these larvae achieve a high degree of cold hardiness.

\section{Changes in sugar and glycogen contents under field and acclimated conditions}

In overwintering larvae, the major sugar was trehalose and the major polyol was glycerol. Figure 2A shows the profiles of glycerol and trehalose contents in the haemolymph of overwintering larvae. Glycerol content differed significantly during the overwintering season $(F=48.88, p<0.001)$. Glycerol was scarcely detected in September and October, but the content was $74.7 \mu \mathrm{mol} / \mathrm{ml}$ in November, and $94.5 \mu \mathrm{mol} / \mathrm{ml}$ in December. Then, the content reached $293.0 \mu \mathrm{mol} / \mathrm{ml}$ in January, representing a 3 -fold increase over that in the previous month $(p<0.05)$. The trehalose content in the haemolymph remained constant with a mean value of $64.9 \mu \mathrm{mol} / \mathrm{ml}$ from September to January $(F=2.29, p=0.079)$.

Figure $3 \mathrm{~A}$ shows the effect of acclimation temperatures on glycerol contents in the diapausing larvae collected in October. Glycerol content changed significantly among the acclimated temperatures $(F=17.60, p<0.001)$. The $0^{\circ} \mathrm{C}$-acclimated larvae accumulated higher contents of glycerol in the haemolymph $(72.2 \mu \mathrm{mol} / \mathrm{ml})$ compared with the $10^{\circ} \mathrm{C}$-acclimated larvae $(p<0.05)$, although no significant difference in content was observed among acclimations at higher temperatures $\left(10,20\right.$ and $\left.30^{\circ} \mathrm{C}\right)$.

A significant change in glycogen content was found from September to January $(F=9.69$, $p<0.001$; Fig. 2B). The glycogen content was $174.1 \mu \mathrm{mol} / \mathrm{g}$ in September, and then decreased
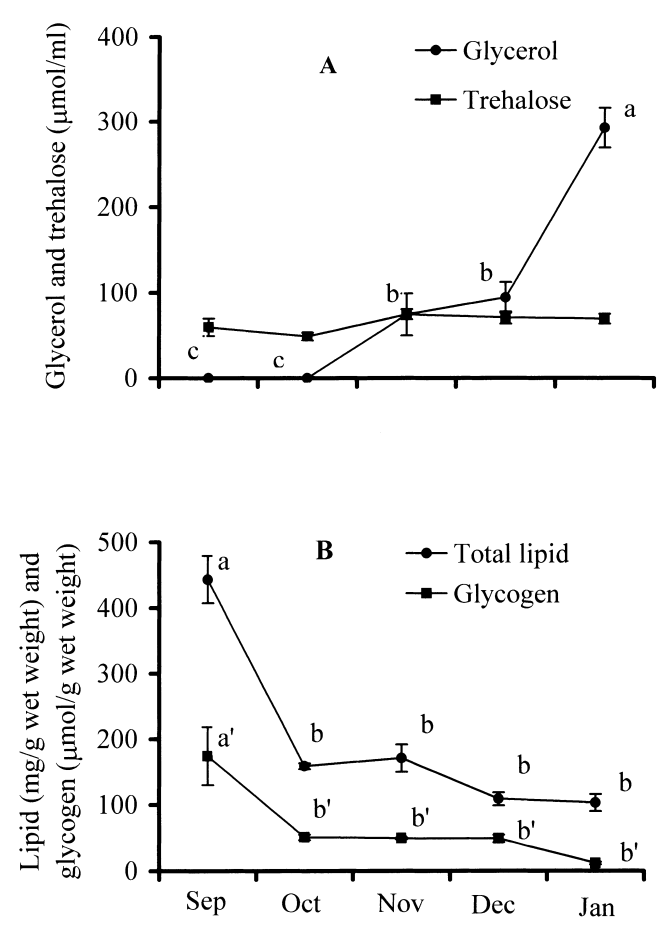

Fig. 2. Seasonal changes in the contents of glycerol and trehalose in haemolymph (A) and total lipids and glycogen (B) in whole-bodies of overwintering larvae of the rice stem borer C. suppressalis. Each symbol shows the mean value ( \pm SEM) of eight replicates. Values labeled with the same letters on the same line are not significantly different at the $5 \%$ level by Tukey's test after ANOVA.

drastically in October at $50.6 \mu \mathrm{mol} / \mathrm{g}(p<0.05)$. Afterward, the content remained constant from October to December, and then decreased slightly from December to January ( $p>0.05)$.

Significant differences in glycogen contents were detected among the various acclimation temperatures $(F=16.43, p<0.001$; Fig. 3B). The glycogen content of larvae acclimated at $10^{\circ} \mathrm{C}$ $(49.8 \mu \mathrm{mol} / \mathrm{g})$ was not significantly different from that of larvae acclimated at $20^{\circ} \mathrm{C}(58.8 \mu \mathrm{mol} / \mathrm{g})$. Acclimation at $0^{\circ} \mathrm{C}$ reduced the glycogen content significantly to $33.9 \mu \mathrm{mol} / \mathrm{g}$ compared with the acclimation at $10^{\circ} \mathrm{C}(p<0.05)$. The glycogen content at $30^{\circ} \mathrm{C}$ also decreased more than that at $20^{\circ} \mathrm{C}$ $(p<0.05)$.

\section{Changes in lipid content under field and accli- mated conditions}

A significant change in lipid content was found from September to January $(F=49.34, p<0.001$; Fig. 2B). The total lipid content of field-collected larvae was $443.2 \mathrm{mg} / \mathrm{g}$ in September, and then de- 

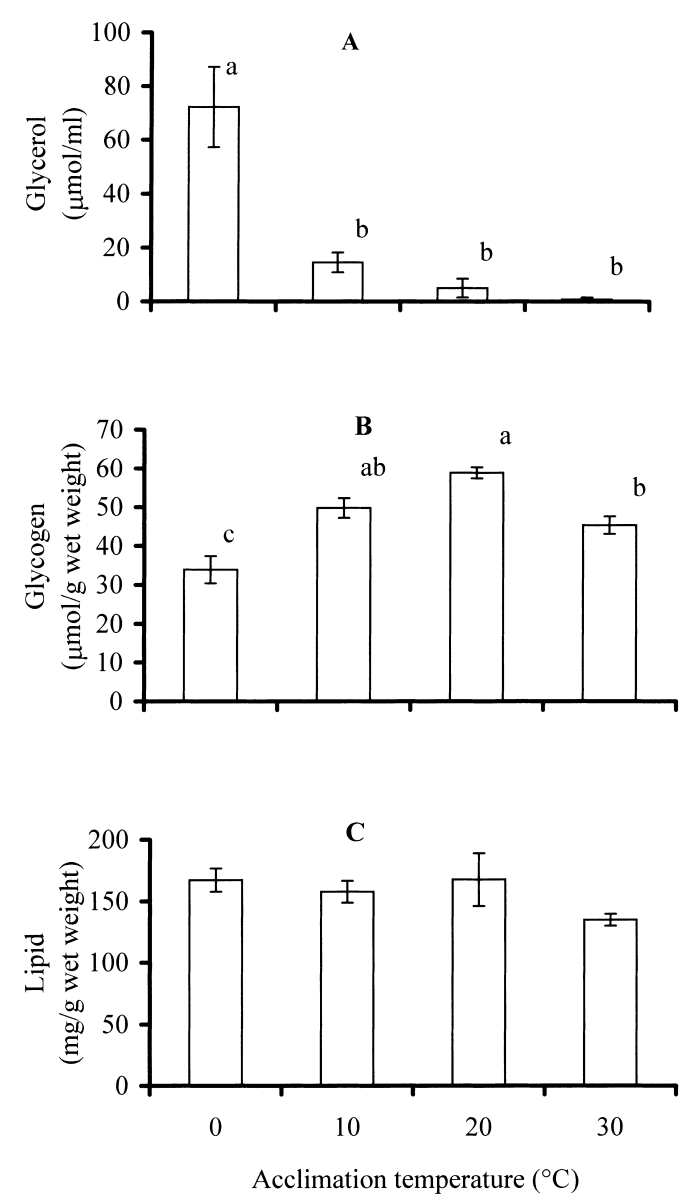

Fig. 3. Effect of acclimation temperature on the contents of glycerol in haemolymph (A), glycogen (B) and total lipids (C) in whole-bodies of the rice stem borer C. suppressalis. Larvae were collected from the field in October and then acclimated at $0,10,20$ or $30^{\circ} \mathrm{C}$ for 15 days. Each symbol shows the mean value $( \pm$ SEM) of eight replicates. Values labeled with the same letters on the same line are not significantly different at the 5\% level by Tukey's test after ANOVA.

creased sharply in October at $158.8 \mathrm{mg} / \mathrm{g}(p<$ $0.05)$. After that, the content was almost constant from October to December, and then decreased slightly from December to January at $103.1 \mathrm{mg} / \mathrm{g}$ $(p>0.05)$.

Figure $3 \mathrm{C}$ shows the effects of acclimation temperatures on the lipid contents of field-collected larvae in October. No significant changes were detected in lipid contents in the full range of acclimation temperatures $(F=1.44, p=0.25)$, although acclimation at $30^{\circ} \mathrm{C}$ caused a slight decrease compared with that at other temperatures.

\section{DISCUSSION}

The Shonai ecotype of $C$. suppressalis has a shorter diapause duration than the Saigoku ecotype, terminating diapause after the cold season in February (Fukaya and Mitsuhashi, 1961). The Shonai ecotype terminates diapause in November when the mean ambient temperature $\left(8.5^{\circ} \mathrm{C}\right)$ is below the threshold temperature $\left(10-12^{\circ} \mathrm{C}\right)$ for larval development (Kishino, 1974). This suggests that the Shonai ecotype does not require a low temperature (below $8.5^{\circ} \mathrm{C}$ ) to terminate diapause.

The Saigoku ecotype shows a high level of cold hardiness at the diapause stage (Tsumuki, 1990), whereas the Shonai ecotype shows a low level of cold hardiness at the diapausing stage, but a relatively high degree of cold hardiness at the post-diapausing stage. Overwintering insects often accumulate polyols and sugars, such as glycerol and trehalose, as cryoprotectants to endure cold stress. In the Saigoku ecotype larvae, glycerol accumulation is closely related to diapause phenomena (Tsumuki and Kanehisa, 1978, 1980; Tsumuki, 1990). In the Shonai ecotype, however, glycerol was not detected in field-collected larvae at the diapause stage, whereas it accumulated to a high level at the postdiapause stage. The same case was also found in the oriental corn borer Ostrinia furnacalis (Goto et al., 2001). Glycerol contents in O. furnacalis larvae at the post-diapause stage were higher than those at the diapause stage. These findings suggest that, in the Shonai ecotype, larvae of $C$. suppressalis at the post-diapause stage seem to divert more carbon sources to glycerol synthesis than do larvae at the diapause stage, and glycerol accumulation is not closely associated with the diapause stage. The different contents of glycerol in field-collected larvae indicate that low temperature (near $0^{\circ} \mathrm{C}$ ) is an important factor for triggering glycerol accumulation in the Shonai ecotype larvae. It is impossible for the larvae to be exposed to low temperatures (near $0^{\circ} \mathrm{C}$ ) in the field from September to October (the average ambient temperature is about $19-16^{\circ} \mathrm{C}$ ), thus, glycerol was not detected in larvae collected from September to October. However, the average ambient temperature is about $0^{\circ} \mathrm{C}$ in January, which is lower than that in December $\left(5^{\circ} \mathrm{C}\right)$, while glycerol content in January $(293.0 \mu \mathrm{mol} / \mathrm{ml})$ was higher than that in December $(94.5 \mu \mathrm{mol} / \mathrm{ml})$. These results suggest that glycerol accumulation in 
the Shonai ecotype larvae is optimal at low temperatures near $0^{\circ} \mathrm{C}$.

Under field conditions, a maximal decrease in glycogen was found from September to October, but a maximal accumulation of glycerol occurred from December to January. Similar phenomena have been discovered in other overwintering insects, such as Epiblema scudderiana and Chasmias sp. (Ohyama and Asahina,1972; Rickards et al., 1987). This suggests that glycogen is converted into not only glycerol but also other substances. Glycogen was converted to glycerol in diapausing larvae (in October) acclimated at $0^{\circ} \mathrm{C}$. However, on a carbon basis, the loss of glycogen was less than the gain of glycerol. This may be because the glycogen content in acclimated larvae $\left(0^{\circ} \mathrm{C}, 15\right.$ days) had already decreased in the field. The lipid contents in field-collected and temperature acclimated larvae suggest that lipid is not related to cold hardiness in overwintering borers.

In summary, larvae of the Shonai and Saigoku ecotype of $C$. suppressalis have different diapause and cold hardiness characteristics. Further studies are needed to elucidate the mechanisms responsible for these differences. Understanding the changes in activities of enzymes for glycogen degradation and glycerol accumulation in field-collected and acclimated larvae should be helpful in this regard.

\section{ACKNOWLEDGEMENTS}

Yi-Ping Li was a recipient of a post-doctoral fellowship from the Japan Society for the Promotion of Science (No. P 99339). Thanks to Mr. K. Ueno (Yamagata Prefectural Agricultural Research Center) for assistance in collecting the rice stem borer. This study was partly supported by a Grant-in-Aid for Scientific Research (B) No. 09556011 to Michiyo Goto.

\section{REFERENCES}

Chen, C. P., D. L. Denlinger and R. E. Lee (1987) Responses of nondiapausing flesh flies (Diptera: Sarcophagidae) to low rearing temperatures: developmental rate, cold tolerance, and glycerol concentrations. Ann. Entomol. Soc. Am. 80: 790-796.

Denlinger, D. L. (1991) Relationship between cold hardiness and diapause. In Insects at Low Temperature (R. E. Lee and D. L. Denlinger eds.). Chapman \& Hall, New York, pp. 174-198.

Fukaya, M. and J. Mitsuhashi (1961) Larval diapause in the rice stem borer with special reference to its hormonal mechanism. Bull. Nat. Inst. Agric. Sci. (Ser. C) No. 13: $1-32$.

Goto, M. (1995) Ecology of barnyard grass stem borer, Enosima leucotaeniella (Ragonot) (Lepidoptera: Pyrali- dae). X. Seasonal changes in trehalose concentration and volume of haemolymph in overwintering larva. Jpn. J. Appl. Entomol. Zool. 39: 264-266 (in Japanese with English summary).

Goto, M., M. Fujii, K. Suzuki and M. Sakai (1998) Factors affecting carbohydrate and free amino acid content in overwintering larvae of Enosima leucotaeniella. J. Insect Physiol. 44: 87-94.

Goto, M., Y. Sekine, H. Outa, M. Hujikura and K. Suzuki (2001) Relationships between cold hardiness and diapause, and between glycerol and free amino acid contents in overwintering larvae of the oriental corn borer, Ostrinia furnacalis. J. Insect Physiol. 46: 157-165.

Goto, M., K. Takahashi and C. Suzuki (1993a) Ecological study on the barnyard grass stem borer, Enosima leucotaeniella (Ragonot) (Lepidoptera: Pyralidae). VIII. Seasonal changes of carbohydrate contents in overwintering larvae. Appl. Entomol. Zool. 28: 417-421.

Goto, M., K. Takahashi and C. Suzuki (1993b) Ecological study on barnyard grass stem borer Enosima leucotaeniella (Ragonot) (Lepidoptera: Pyralidae). IX. Effect of temperature on carbohydrate contents in diapausing and early post-diapausing larvae. Appl. Entomol. Zool. 28: 433-437.

Inoue, T. and S. Kamano (1957) The effect of photoperiod and temperature on the induction of diapause in the rice stem borer, Chilo suppressalis Walker. Jpn. J. Appl. Entomol. Zool. 1: 100-105 (in Japanese with English summary).

Ishikura, H. (1955) On the types of the seasonal prevalence of rice stem borer moth in Japan. Bull. Nat. Inst. Agric. Sci. (Ser. C) No. 5: 67-80.

Kishino, K. (1974) Ecological studies on the local characteristics of the seasonal development in the rice stem borer Chilo suppressalis Walker. Bull. Tohoku Agric. Exp. Stn. 47: 13-114 (in Japanese with English summary).

Koštál, V. and P. Šimek (1995) Dynamics of cold hardiness, supercooling and cryoprotectants in diapausing and nondiapausing pupae of the cabbage root fly, Delia radicum L. J. Insect Physiol. 41: 627-634.

Leather, S. R., K. F. A. Walters and J. S. Bale (1993) The Ecology of Insect Overwintering. Cambridge University Press, Cambridge. 255 pp.

Nordin, J. H., Z. Cui and C.-M. Yin (1984) Cold-induced glycerol accumulation by Ostrinia nubilalis larvae is developmentally regulated. J. Insect Physiol. 30: 563-566.

Ohyama, Y. and L. Asahina (1972) Frost resistance in adult insects. J. Insect Physiol. 18: 267-282.

Rickards, J., M. J. Kelleher and K. B. Storey (1987) Strategies of freeze avoidance in larvae of the goldenrod gall moth, Epiblema scudderiana: winter profiles of a natural population. J. Insect Physiol. 33: 443-450.

Tauber, M. J., C. A. Tauber and S. Masaki (1986) Seasonal Adaptations of Insects. Oxford University Press, New York, Oxford. 411 pp.

Tsumuki, H. (1990) Environmental adaptations of the rice stem borer, Chilo suppressalis and the blue alfalfa aphid, Acyrthosiphon kondoi to seasonal fluctuations. In $\mathrm{Ad}$ vances in Invertebrate Reproduction 5 (M. Hoshi and O. Yamashita eds.). Elsevier Science Publishers, Amster- 
dam, pp. 273-278.

Tsumuki, H. and K. Kanehisa (1978) Carbohydrate content and oxygen uptake in larvae of rice stem borer, Chilo suppressalis Walker. Ber. Ohara Inst. Landwirt. Biol. Okayama Univ. 17: 98-110.

Tsumuki, H. and K. Kanehisa (1979) Glycerol concentration in haemolymph of hibernating larvae of the rice stem borer, Chilo suppressalis Walker: Effects of ligation and cold tolerance. Appl. Entomol. Zool. 14: 497-499.

Tsumuki, H. and K. Kanehisa (1980) Effect of low temperature on glycerol and trehalose concentration in haemolymph of the rice stem borer, Chilo suppressalis Walker. Jpn. J. Appl. Entomol. Zool. 24: 189-193 (in Japanese with English summary). 